\title{
La recuperación de la Memoria Histórica en las series de ficción a través de las redes sociales: el caso de España y Chile
}

\author{
Miguel Chamorro Maldonado, Universidad de Valparaíso, Chile
}

\begin{abstract}
Resumen: El momento que viven las series de ficción en televisión es auspicioso gracias a su calidad temática, técnica y profesional, y un ejemplo de ello son las series de carácter histórico. Su producción no sólo involucra proyectar el producto por la pantalla chica, sino además realizar un trabajo benéfico a través de la distribución de sus contenidos por las redes sociales, generando un contacto activo con los televidentes que son al mismo tiempo, seguidores en las respectivas plataformas digitales. En esta comunicación se desarrolla un estudio sobre el rescate de la memoria histórica en las series de ficción a través de las redes sociales por Internet. La muestra corresponde a las series españolas Amar es Para Siempre y Cuéntame Cómo Pasó, donde se aplicó un análisis de contenido al discurso para comprender bajo qué variables, los usuarios profundizan sobre el rescate de la memoria en las redes sociales.
\end{abstract}

Palabras claves: memoria histórica, redes sociales, ficción, construcción social, usuarios

\begin{abstract}
The time living fiction series on television is auspicious because its subject, technical and professional quality, and an example of this is the series of historical character. Its production involves not only designing the product for the small screen, but also do charitable work through the distribution of their content through social networks, generating an active contact with viewers who are both followers in the respective platforms digital. In this paper a study on the recovery of historical memory in fiction series through Internet social networks develops. The sample corresponds to the Spanish series Amar es para siempre and Cuéntame Cómo Pasó, which it has been applied to the speech content analysis to understand what variables, users delve on the recovery of memory in social networks.
\end{abstract}

Keywords: Historical Memory, Social Networks, Fiction, Social Construction, Users

\section{Introducción}

$\mathrm{L}$ a producción de contenidos basados en la memoria histórica resulta ser un avance en las realizaciones audiovisuales, generando impacto en las audiencias que conlleva una variada y creciente oferta en la producción de contenidos reflejados en los distintos medios interactivos, aprovechando así procesos de convergencia y trasmedialidad en los modelos.

Como consecuencia, la historia y su memoria se instalan como temas en las series de ficción en los últimos años dentro de la programación de las parrillas programáticas de las cadenas de televisión.

Debido a esto, uno de los principales objetivos del presente proyecto de estudio es obtener una comprensión del sentido de la memoria reciente desde la perspectiva de los propios usuarios en las redes sociales, teniendo en cuenta sus aspectos afectivos y expresivos hacia las series.

Además, el propósito de esta comunicación es observar si la memoria reciente forma parte de un conocimiento global de distintas generaciones de usuarios que manifiestan un interés en revelar una representación social sobre los comportamientos expresados en las redes sociales.

En este sentido, el grado de representatividad, entendida como la identificación de intereses particulares supeditados por una marca, huella, sello o construcción lingüística del usuario, resulta esencial al momento de comprender la identidad que articula en el feed back comunicativo que ofrece la red debido a la promoción de las series de ficción histórica.

Es por ello que la presente comunicación, indaga aquellos discursos válidos en la conformación de una participación social e interactiva que busca recobrar la memoria histórica que aparentan mostrar las series de ficción.

Revista Internacional de Tecnología, Ciencia y Sociedad

Volumen 5, Número 1, <http://tecnociencia-sociedad.com>, ISSN 2530-4895

(C) Global Knowledge Academics. Miguel Chamorro Maldonado

Todos los Derechos Reservados Permisos: soporte@gkacademics.com 


\section{Ficción al alcance de la tecnología}

En términos generales la tecnología suele acelerar situaciones y procesos, facilita almacenar información y comunicar al mismo tiempo, reduciendo el tiempo y el espacio o motivar el acompañamiento como acción de la vida cotidiana. Sin embargo, uno de los aspectos significativos es que reinventa las formas de relacionamiento social y disposiciones de actuar.

Las tecnologías nos hace diferentes, reconfigura la forma de ver y escuchar, pero sin dejar de lado las costumbres de observar y comunicar. Estamos ante una forma de organización social nueva donde la sociedad se reconstruye rápidamente gracias al mejoramiento y procedimiento del paradigma digital.

En este nuevo contexto donde los medios de comunicación influyen y se mantienen vigentes en el modelo de construcción de un perfil y una imagen como fenómeno psicosocial, la proliferación de la comunicación digital junto con la conectividad incide en que las nuevas tecnologías desarrollen temáticas y prácticas sociales en los usuarios para configurar una identidad, consumo, manifestaciones, nuevas formas de sociabilidad y construcción de un perfil de sí mismo.

Una de las temáticas válidas que se discuten en las redes sociales se relacionan con tópicos vinculados al entretenimiento, pero las áreas de la economía, los asuntos sociales o culturales como contenidos, también forman parte de la distribución rápida que realizan los medios de comunicación.

En este marco vertiginoso que producen las tecnologías, la búsqueda de una representación que generan los contenidos audiovisuales de la televisión contemporánea, específicamente en programas relacionados con series de ficción histórica, presenta una notable transformación la producción en los últimos años no sólo en el visionado, sino además en los comentarios que despiertan un interés inmediato.

Esto ha provocado una atracción estratégica en las producciones para el consumo cultural y ocio en los televidentes, abriendo el debate en determinados temas donde todos pueden hablar en el enjambre del ecosistema comunicativo.

En el presente ecosistema, la creatividad de la producción audiovisual en la ficción es favorable ya que cuenta con una maduración temática, técnica y profesional, además de una rápida convergencia de narración que abre espacios de comunicación en las redes sociales.

La consecuencia es el fulminante desarrollo de Internet que ha encontrado un entorno interactivo donde lleva una comunicación multidireccional como parte del nuevo ecosistema comunicativo que enfrentan los medios de comunicación, las redes sociales y las personas para dar pie al sentido de la memoria reciente desde la perspectiva de los usuarios en la redes sociales y los televidentes que participan del engranaje de la sociedad, la cultura y la tecnología.

Las series de ficción al estar presente en el motor social, presentan toda una promoción hacia la caracterización de personajes, debates sobre temáticas o informaciones que resultan ser un material atractivo para el funcionamiento comunicacional que desarrollan en el plan tecnológico como parte del ecosistema comunicativo.

Por otra parte, las temáticas de contenido histórico hacen inexorable que los usuarios no evadan la nostalgia, ocupando una buena parte de las plataformas comentarios alusivos al recuerdo de la vida cotidiana reciente o hechos de la historia, motivados por series que reúnen estos contenidos.

En este contexto, las redes sociales cobran una especial relevancia en los usuarios que participan en cada minuto de exhibición de alguna serie de ficción de televisión. Las plataformas digitales resultan ser un espacio de convivencia y participación social mientras se transmite un programa, reforzando la interacción.

De esta forma, las redes sociales han cambiado el modo de las relaciones y la forma de absorber un producto audiovisual. Como consumo cultural, las personas buscan compañía a través de los nuevos medios sociales que cada día son más fáciles y asequibles de usar.

Ello genera que las series en las redes sociales cumplan el rol en la estructura social, entregando información y actuando como mediadores entre el mundo real y lo representado.

En este contexto, como cualquier serie de ficción existen factores que se erigen como pilares fundamentales para que la audiencia manifieste una cercanía con la producción en aspectos intrínsecos a la propia identidad, pero también a componentes temáticos. 
La producción audiovisual está al alcance de la tecnología. Las series de ficción se distribuyen entre la televisión y las redes sociales, donde la opinión, los comentarios y/o el punto de vista son parte del juego social participativo en aquellas producciones de carácter histórico, construyendo así una recuperación de la memoria, gracias al sistema digital que proporciona el paradigma del ecosistema comunicativo que vive la sociedad en la actualidad.

\section{Memoria en los Medios de Comunicación}

La instalación de la memoria en una sociedad no abarca todo el pasado, sino también aquello que sigue viviendo entre nosotros. Y una de las formas que aquellas vivencias sigan activas en la memoria de la sociedad es a través de la labor que ejercen los medios de comunicación, sean estos convencionales o electrónicos, donde su mirada al pasado trae consigo que el tiempo adquiera una importante dimensión social por las referencias que concita este tipo de cuestiones.

Ahora bien, la memoria para comprenderla cuando nos habla del pasado requiere de un soporte, y en la actualidad, el alcance de la memoria histórica con el tiempo presente, logra su comprensión con las huellas o registros que permiten desarrollar un funcionamiento social ${ }^{1}$ del objeto.

No cabe duda que materiales como documentos, fotografías, películas, planos, objetos antiguos, entre otros, permiten construir una rica herencia colectiva que contiene expresiones que despierta aprecio e identidad. En este sentido, los bienes que integran la identidad cultural, son puestos como valor desde el punto de vista de las emociones, ya que conforman un patrimonio que es revalorizado por todos los miembros de la sociedad.

Cuando los individuos perciben que la memoria llega a través de la comunicación, ya sea por diversos registros y medios que implica estar presente frente al pasado, se genera una memoria comunicativa $^{2}$ proveniente desde afuera donde los sujetos experimentan sentidos variados, estableciendo nexos internos y externos.

En las sociedades modernas y postmodernas las fuentes de la historia son mediáticas o los relatos recogidos se distribuyen a través de instituciones de nivel público.

González Callejas (2013) plantea que en la actualidad estamos en presencia de una sociedad que acude a la memoria como un fetiche de consumo para recuperar el pasado, es decir, la cultura de masas aprovecha su uso a través del turismo, el libro y los espectáculos como el cine. Este consumo de reminiscencias lo denomina como la "era del coleccionismo de recuerdos", un culto del marketing y auge sobre comportamientos pasados.

El investigador habla sobre la existencia de una mercantilización masiva de la nostalgia donde el relato actual que alude a la memoria, ha podido aprovechar la rehabilitación de las historias de centros urbanos y registros de la vida cotidiana a través del video, la fotografía digital, documentales, docudramas y sitios de Internet. Su juicio lo asocia al sistema propio de la posmodernidad donde las huellas e imágenes que se mantienen almacenadas para rememorar el pasado, ha generado una inflación abultada de la función de la memoria.

Sin embargo, no se puede desconocer que los recuerdos es materia de interés para los medios de comunicación que la invoca, a través de sus autores, con formatos como documentales, la ficción, reportajes televisivos, programas radiofónicos, Internet y, actualmente, los propios usuarios utilizan los chats o mensajes en las redes sociales para comentar temáticas con contenidos históricos. ${ }^{3}$

\footnotetext{
${ }^{1}$ El académico Josep Lluís Facé Gomez de la Universidad de Girona, utilizó este concepto en la mesa redonda "Televisión Studies: Quality, Transmediality and beyond" realizado en la Facultad de Comunicación de la UAB en el marco del Doctoral SummerSchool, junio 2013, aludiendo a que en la actualidad existe una audiencia expandida que se fragmenta en la búsqueda de una autenticidad donde existen programas que representan la cotidianidad del pasado.

${ }^{2}$ Véase Duch y Chillón (2012), Un ser de mediaciones, sobre las referencias de Jan Assmann, pág.414, quien entrega una visión pedagógica sobre la memoria cultural que deriva de dimensiones externas, entendida la cultura como un proceso amplio de comprensión.

${ }^{3}$ Véase YouTube los discursos de Adolf Hitler o vídeos vinculados a la Segunda Guerra Mundial u otros contenidos con temáticas del pasado.
} 
La industria de la comunicación se caracteriza por tener una singularidad al condicionar su funcionamiento donde el contenido de la comunicación en sí, es fundamental, para llegar a las audiencias. Este aspecto es lo que conlleva a que los medios, en materia del tratamiento de la memoria, cumpla con tres funciones fundamentales: seducción informativa, visión de nostalgia y representación de lo extremo.

En este sentido Sánchez-Biosca (2006), atribuye algo singular sobre los medios visuales que aluden a la memoria:

Asienta y cristaliza ciertos aspectos de la memoria colectiva, operando por selección entre imágenes, convirtiendo alguna de ellas en emblemas de valores, ideas, mediante abstracción, estimular respuestas diferentes y expectativas también diversas. (Sánchez-Biosca, 2006, p. 14).

Temáticas sobre la memoria han sido aprovechadas para contar historias que representan una verdad ocurrida en el pasado donde el cine, siguiendo la línea de la fotografía, fue el medio principal que comenzó un trabajo de registro para informar y convertirse al mismo tiempo, en una fuente del pasado, independiente de sus leyes y códigos, completamente diferentes a la hermenéutica de la historia.

Fuera de las normativas que invocan a explicaciones universales, el cine cumple una doble función al ser un agente de la historia y fuente de la misma, donde no pierde la oportunidad para recurrir al presente con el fin de configurar historias del pasado basadas en hechos reales.

Aunque el documento escrito logra ser una fuente significativa, la ficción también cumple un rol fundamental, porque el film es un testimonio desde el momento en que la cámara revela el funcionamiento real de la sociedad o de la gente que forma parte de ella.

Obviando la parte metodológica como plantea Marc Ferro (1980), el imaginario que proyecta la ficción puede definir elementos de una realidad que constituye un material esencial para la historia.

Los medios audiovisuales en general y los de información, han tenido un papel esencial para este tipo de casos, ya que cumplen una fijación con la memoria colectiva, lo que permite armonizar la reconstrucción de los hechos.

La investigadora Rosa María Ganga (2008) admite que los recuerdos y acontecimientos históri$\cos$ son materia disponible para los medios audiovisuales para que ciertos hechos sean reconstruidos como vehículos hegemónicos de las informaciones que recibe, lo que resulta fundamental la participación de personas preparadas para dar claridad a lo que se relata.

Por otra parte, fuera de reconocer el trabajo iniciado por el cine al desarrollar discursos en la línea de argumentos históricos y/o político, Francesca Anania (2010) reconoce que los medios de comunicación en general, funcionan de acuerdo a la evolución que va desarrollando la sociedad en el contexto de cada época, lo que permite moldear a quienes integran una colectividad.

Si observamos el interés y visión que realizan los medios de comunicación por la memoria, la investigadora italiana precisa que:

Los medios se constituyen como una documentación de la realidad al menos en dos niveles: ya que reflejan esta realidad, en el sentido que la registran y la convierten en analizable y dado que, representándola, la filtran a través de una serie de categorías mentales que se vinculan directamente con la mentalidad de una época. (Anania, 2010p. 18).

De esta forma el medio pasa a ser un agente de la historia, pero al mismo tiempo un redactor de historias en el que confluyen distintos discursos que llevan a una interpretación del contexto. La investigadora sostiene que las fuentes que abordan la memoria en los medios de comunicación pueden ser programas de televisión, películas, artículos, debates que aportan un análisis cuantitativo, pero también cualitativo, ya que la historia genera conciencia en la sociedad.

En este sentido, la función comunicativa de la memoria para algunos autores es un factor decisivo al dimensionar la capacidad que tienen los sujetos para escenificar aquellas materias del pasado que se visualizan en el presente.

Esto permite inferir que la vinculación del tiempo presente de la memoria con los medios de comunicación, como uno de los actores en esta relación con los demás que, según explican Duch y 
Chillón (2012), subyace una documentación de la realidad que se refleja en el sentido de los registros y el material que es posible de ver y analizar.

Por otra parte, como explica Anania (2010), el medio de comunicación funciona como un agente de la historia, pero al mismo tiempo es escritor de una historia que se integra al contexto presente, ya que usa el pasado actualizándolo e interpretando con categorías de la contemporaneidad presente.

En el marco de la cultura occidental, la pequeña pantalla ha creado modos de entendimiento significativo sobre el pasado no sólo en Europa luego de la Segunda Guerra Mundial, sino además en casos específicos de algunos países como en Francia y la época de la resistencia, en Bélgica el apoyo de los flamencos a los nazis o las causas de la Guerra Civil en España y sus posteriores consecuencias.

En términos más claros y como una forma de comprender el conocimiento que puede generar la memoria, esta resulta un tópico para la producción de productos audiovisuales. Desde el punto de vista de la industria cultural, según lo indica Bourdieu (2012), saca provecho ya que articula una memoria social que intenta erigirse como verdad.

Por otro lado, existe un interés por ver la historia con una intensión casi sentimental, proclive a la nostalgia e idealización, teniendo en cuenta que existen algunos pasados que resultan difíciles de mantener, debido a su crudeza y dolor causada por miles de muertes.

Según señala Elena Yestes (2009) hay una sobre abundancia de memoria en concordancia con el discurso que intenta recuperar la historia. Dicho discurso se aprecia en las instituciones políticas y de poder, pero al mismo tiempo en los medios de comunicación que se vuelcan hacia una tendencia de revisión colectiva.

En este sentido, la asociación que se hace sobre la memoria en los medios de comunicación, en algunas situaciones tiene un acercamiento más de nostalgia o sentimiento. Dicha melancolía se refleja en algunas argumentaciones de programas de series de ficción, sin desconocer que éstas no pierden sus normativas de desarrollo - personajes con argumentos que conllevan amor y dramas -, pero que ciertas escenas donde los actores demuestran algunas conductas, despiertan el recuerdo almacenado en la memoria.

Hay autores que describen la memoria como un factor esencial de una identidad, pero no solo desde el punto de vista hereditario, sino también "geocultural" como lo plantean Duch y Chillón.

Esta condición genera un proceso que se percibe desde un nexo que se relaciona con el ámbito histórico-cultural, que es conocido por quienes disponen de aquellas características ${ }^{4}$ transmitidas de generación a generación.

Cuando participa el medio de comunicación, Yestes la denomina como memoria mediada (2009), aquella donde el relato recae en los periodista, quienes cumplen una función distinta a la de los historiadores, ya que éstos no desarrollan un trabajo científico, pero contribuyen con documentar diariamente elementos de la realidad que, finalmente, se convierten en un documento esencial para la historia que puede traer consigo, "el poder y la influencia que ejercen los medios de comunicación como narradores y escultores de la realidad social actual, pero también de la realidad pasada" (Yestes, 2009, p. 75).

La investigadora no duda que en la actualidad el rol que juegan los medios de comunicación para acudir a una memoria histórica que registran la realidad con sus cámaras de cine, televisión y también Internet y sus vídeos, forma parte de una agenda temática que nos lleva a la información, pero también a la entretención, al exponer ciertas imágenes de la historia al servicio del público. ${ }^{5}$

En este sentido, si observamos las series de ficción de carácter histórico que tienen una buena producción de guion y relato, podemos afirmar que aportan un estándar a la memoria cuya virtud es realizar un visionado en retrospectiva de situaciones que llaman la atención por el recuerdo, en términos de moda, censura, crisis económica, miedos, etc.

\footnotetext{
${ }^{4}$ Común en este tipo de transmisión son las historias o cuentos transmitidos por los abuelos como celebraciones populares o fiestas religiosas donde las iglesias la convierten en una verdadera tradición, como por ejemplo, festividades de Semana Santa o Asunción de la Virgen.

5 "El discurso de la Memoria Histórica en los Medios de Comunicación". Congreso "I+C Investigar la Comunicación". Asociación Española de Investigación. En http://www.ae-ic.org/santiago2008/contents/pdf/comunicaciones/390.pdf.
} 
Asimismo, la marcha de la historia se ha convertido en un componente más para la interactividad producida por las nuevas tecnologías de la comunicación, generando un positivo pronóstico para la televisión, principal medio vinculado a la producción de series de ficción u otros formatos que tratan la memoria. La convergencia entre televisión y redes sociales ha permitido que el espectador-usuario participe en el debate y reflexione sobre aquellos recuerdos aún latentes en el presente. De esta forma, construyen esta idea sobre la marcha, donde los medios de comunicación, conjuntamente con una comunidad virtual, explican y describen la historia que permanece aún en el recuerdo.

Elena Yestes destaca que en la actualidad, con la nueva sociedad de la información y la globalización, conocer el pasado de otros países, es un valor que va en alza, sobre todo con la globalidad que presentan los medios de comunicación para acceder a la información.

Los canales de acceso a la información se han multiplicado y diversificado, en consecuencia, actualmente, la historia se puede explicar de muchas maneras, porque existen múltiples canales preparados para ello. ${ }^{6}$

La memoria reviste un carácter social, y los medios de comunicación han tomado a la historia, condicionándola al llamado público, moldeando a la sociedad y a las conciencias colectivas a través del discurso.

Como bien sabemos, la representación histórica que ofrecen los medios, se basa en una idea que no busca una verdad absoluta, sino más bien moldear una memoria que contiene imágenes que son transformadas por los actores sociales ${ }^{7}$ en elementos simbólicos como signos de alegorías, revistiendo así, un carácter social.

\section{Metodología}

La metodología que se propone en este apartado es el análisis de contenido del discurso y su relación con la sociedad y la cultura, aplicada en las redes sociales. En este sentido, se recogieron los soportes escritos que exponen los usuarios en las plataformas tecnológicas de las redes sociales.

En este caso se empleó un trabajo de observación que corresponde a las conductas de los sujetos como productor de discursos situado en un espacio social que para este caso, es aplicable a las redes sociales donde se emiten mensajes mientras transcurre la transmisión de las series de ficción españolas seleccionadas. La observación y recogida se llevó a cabo entre abril y julio de 2013.

Cabe señalar que el presente estudio forma parte de un estudio comparativo de la recuperación de la memoria histórica en series de ficción entre España y Chile, pero de acuerdo a la parrilla programática de las respectivas cadenas de televisión, las ficciones de Chile no han sido integradas en el presente estudio debido a que sus emisiones están programadas para fines de 2013 e inicio de 2014.

\section{Antecedentes de las series de ficción}

Amar es para Siempre, es una serie de ficción donde el relato transcurre a través de las vivencias y tramas que coexisten a sus personajes en un momento histórico y de esplendor en la reconstrucción de una España gobernada por Franco en la década del 60 con un resurgimiento social y económico de la población.

La serie es la continuación de la reconocida producción Amor en Tiempos Violentos que se emitía TVE, manteniendo un sello de época, con incorporaciones de personajes a medida que transcurren las historias para abrir diversas tramas que viven los personajes en los inicios de los 60 .

En tanto, Cuéntame Cómo Pasó, es una de las producciones más importantes del panorama audiovisual español que cuenta la historia del país a través de una familia en el seno de los años 60 con

\footnotetext{
${ }^{6}$ Ibídem.

${ }^{7}$ Manuel Castells (2009) en su obra Comunicación y Poder reflexiona sobre la importancia de los actores sociales en las redes de mente y poder, págs. 191-259.
} 
la intención de comenzar desde que Massiel ganase el Festival de Eurovisión hasta consolidada la democracia tras la muerte de Franco, consolidando así, un documento testimonial.

En la presente publicación se han considerado los datos de la series de España, ya que las temporadas de las producciones de ficción de Chile aún están en fase de emisión correspondiente a octubre de 2013 a julio de 2014.

\section{Etapa 1}

Esta etapa corresponde a la observación de las redes sociales que contienen mensajes de los usuarios que siguen las series de la presente investigación. Para las producciones españolas, las series corresponden a Cuéntame cómo pasó de RTVE, temporada 14 que se mantuvo al aire desde enero hasta mayo de 2013 los días jueves, y Amar es para Siempre en su primera etapa de la estación televisiva Antena3, transmisión correspondiente de lunes a viernes.

La muestra contempló las siguientes redes sociales vinculadas a la serie Amar es Para Siempre: Facebook Amar es Para Siempre Fans; Facebook Diagonal TV, Foro Formula TV; Momentos Antena 3 y Twitter con su hashtag Amaresparasiempre entre los meses abril y julio de 2013.

Para el caso de la serie Cuéntame Cómo Pasó la muestra se desarrolló en las siguientes redes: Facebook Blog Cuéntame Cómo Pasó; Foro Formula TV y Twitter con el hastage Cuentame entre los meses abril y julio de 2013.

\section{Etapa 2}

Se seleccionaron aquellos mensajes de las audiencias reales que siguen las series de fícción en las redes sociales que estuvieron activas mientras se emitía por televisión de acuerdo a su parrilla programática (Cuéntame Cómo Pasó todos los jueves a las 22:00 horas y Amar es Para Siempre de lunes a viernes de 16:30 a 17:30 horas).

Se estableció como categoría de análisis de contexto, correspondiente a la observación de los mensajes y/o comentarios levantados en las redes sociales. Se incluyó reseñas a fotografías de las secuencias de las escenas, avisos promocionales y tratamientos de temas.

Tomando la idea de Paul Ricoeur (1999) donde la lectura de un discurso textual conduce a una dimensión del habla para interpretar, en este sentido la categoría de discurso seleccionada corresponde a unidades semánticas por temáticas, adaptada para el presente estudio. Se estableció la siguiente unidad: Memoria de Temática Histórica cuya correspondencia se establece mediante el alcance del texto que procede a mencionar hitos históricos del pasado, recuerdos de la vida cotidiana, comparaciones entre hechos institucionales del presente y ocurridos anteriormente al tiempo actual, además de considerar reminiscencias que apelen a la nostalgia.

De esta categoría, se escogieron subtemas que engloban los tópicos más comunes que los usuarios abordan en sus mensajes, desarrollando así ítems en las áreas de la política, situaciones sociales, judiciales, culturales, de diseño o modas. Las marcas de registro para la categoría y subcategoría corresponden a todas aquellos registros determinados por palabras o enunciados claves que vinculan el discurso con el pasado.

\section{Etapa 3}

Se procedió a transcribir íntegramente los discursos recogidos en las distintas redes sociales vinculadas a las series de ficción contempladas en el estudio.

Nivel de Medición: A nivel cuantitativo y cualitativo, la representación se medió a escala numérica ascendente, de acuerdo a la perspectiva recogida por los usuarios a través de los discursos y las categorías establecidas para la presente investigación.

Se consideró la participación social, es decir, aquella donde el sujeto establece un vínculo desde su entorno correspondiente a conductas de acción que se reduce desde la televisión, el ordenador y los mensajes que cobran protagonismo en la interacción inmersa en las redes. 
REVISTA INTERNACIONAL DE TECNOLOGÍA, CIENCIA Y SOCIEDAD

Tabla 1: Número total de mensajes y porcentajes

\begin{tabular}{|l|lc|}
\hline Amar es Para Siempre & $N^{o}$ & $\%$ \\
\hline Facebook Amar es Para Siempre Red Fans & 21 & 38 \\
\hline Facebook Diagonal TV & 1 & 1,8 \\
\hline Foro Formula TV & 16 & 29 \\
\hline Twitter \#Amaresparasiempre & 17 & 30 \\
Momentos Antena3 & 1 & 1,8 \\
\hline TOTAL & 56 & 100,6 \\
\hline
\end{tabular}

Fuente: Elaboración propia, 2013.

La presente muestra indica la cantidad de discursos que los usuarios abordan temáticas de memoria histórica en las respectivas redes sociales analizadas. A través del hashtage de Twitter, los usuarios participan activamente entregando comentarios que evocan a la memoria, dependiendo de la experiencia de navegación y guía complementaría que lleva a formular de manera autónoma una evocación de la memoria.

Figura 1: Mensajes vinculados al recuerdo la memoria
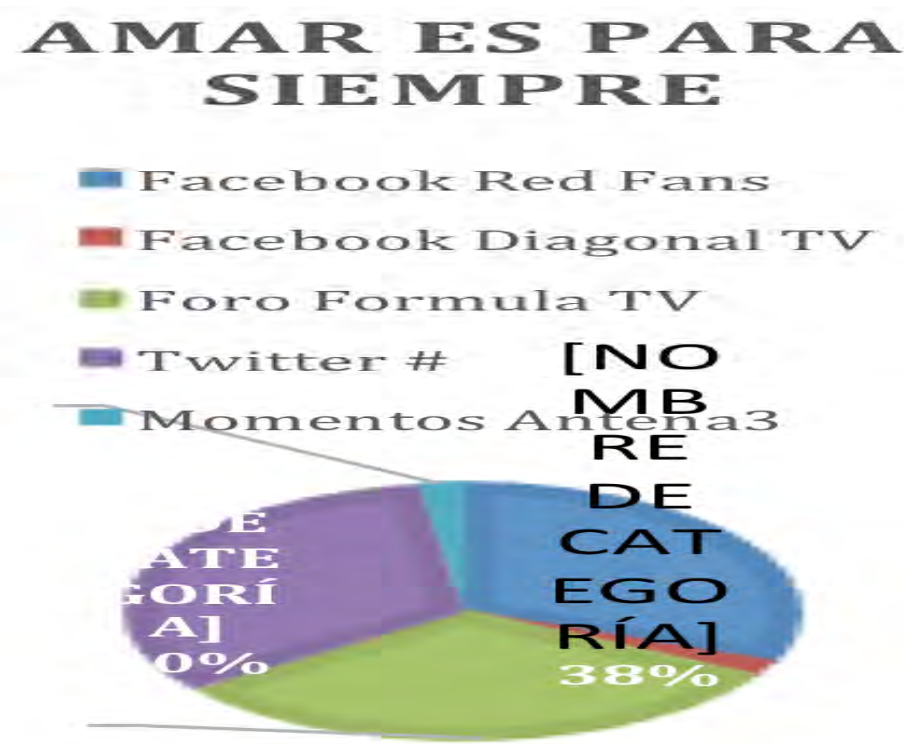

Fuente: Elaboración propia, 2013.

Tabla 2: Número total de mensajes y porcentajes

\begin{tabular}{|l|ll|}
\hline Cuéntame Cómo Pasó & $N^{o}$ & $\%$ \\
\hline Foro Formula TV & 8 & 14 \\
\hline Twitter \# & 49 & 86 \\
\hline TOTAL & 57 & 100 \\
\hline
\end{tabular}

Fuente: Elaboración propia, 2013. 
Figura 2: Mensajes vinculados al recuerdo la memoria

\section{CUÉNTAME CóMO PASó}

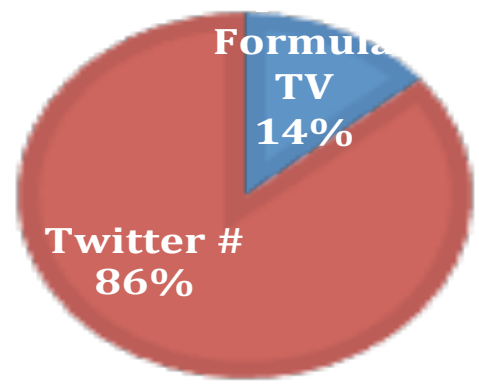

Fuente: Elaboración propia, 2013.

Similar al caso anterior, Twitter concentra una mayor participación de usuarios que discuten aspectos relativos a la memoria histórica que proporcionan los argumentos de la serie Cuéntame Cómo Pasó a través de su hashtage social.

Cabe señalar que la presente serie de ficción, en la observación global a las redes sociales solo contempló discursos vinculados a la memoria histórica en Twitter y Foro Formula TV.

\section{Registro de subcategorías temáticas}

En el marco de la comprensión de la memoria histórica, entendiendo esta como la recreación ligada al contexto político, social, económico y cultural que desarrolla un proceso de rememoración que se evoca socialmente, independiente de su fórmula y estrategia, cuyos acontecimientos ha dejado un rastro en los sujetos por medio del conocimiento, pero también por componentes simbólicos que comparte con sus tradiciones y costumbres en forma social, las series de ficción Amar es Para Siempre y Cuéntame Cómo Pasó reflejan una valoración social, cultural y político que adquiere importancia en las redes sociales como huella sostenible en el tiempo.

En este sentido, observando sus discursos y tomando aquellos elementos como marcas, en la categoría de Memoria de Temáticas Histórica tratada en el presente estudios, se configuraron subcategorías obtenidas en las respectivas redes sociales y que se vinculan estrechamente con los debates tratados a causa de ambas series de ficción.

Gracias a la participación de los usuarios, se incorporaron los presentes valores en la presente tabla de registro:

Tabla 3: Niveles temáticos de la memoria

\begin{tabular}{|l|c|c|c|c|c|c|c|c|}
\hline $\begin{array}{l}\text { REDES } \\
\text { Subcategoría }\end{array}$ & Twitter & $\begin{array}{c}\text { Foro } \\
\text { Formula } \\
\text { TV }\end{array}$ & $\begin{array}{c}\text { Blog } \\
\text { Facebook } \\
\text { Fan }\end{array}$ & $\begin{array}{c}\text { Facebook } \\
\text { Red Fans }\end{array}$ & $\begin{array}{c}\text { Facebook } \\
\text { Diagonal } \\
\text { TV }\end{array}$ & $\begin{array}{c}\text { Momentos } \\
\text { Antena3 }\end{array}$ & TOTAL & $\%$ \\
\hline Justicia & $\mathrm{x}$ & $\mathrm{X}$ & - & $\mathrm{x}$ & - & - & 18 & 16 \\
\hline Política & $\mathrm{x}$ & $\mathrm{X}$ & - & $\mathrm{x}$ & - & $\mathrm{x}$ & 33 & 28 \\
\hline Cultura & $\mathrm{x}$ & $\mathrm{X}$ & - & & - & - & 31 & 27 \\
\hline $\begin{array}{l}\text { Situaciones } \\
\text { Sociales }\end{array}$ & $\mathrm{x}$ & $\mathrm{X}$ & - & $\mathrm{x}$ & - & - & 30 & 26 \\
\hline $\begin{array}{l}\text { Diseño / } \\
\text { Moda }\end{array}$ & $\mathrm{x}$ & - & - & - & $\mathrm{x}$ & - & 4 & 3 \\
\hline TOTAL & & & & & & & $\mathbf{1 1 6}$ & $\mathbf{1 0 0}$ \\
\hline
\end{tabular}

Fuente: Elaboración propia, 2013. 
Figura 3: Porcentaje niveles temáticos memoria

\section{REDES SOCIALES}
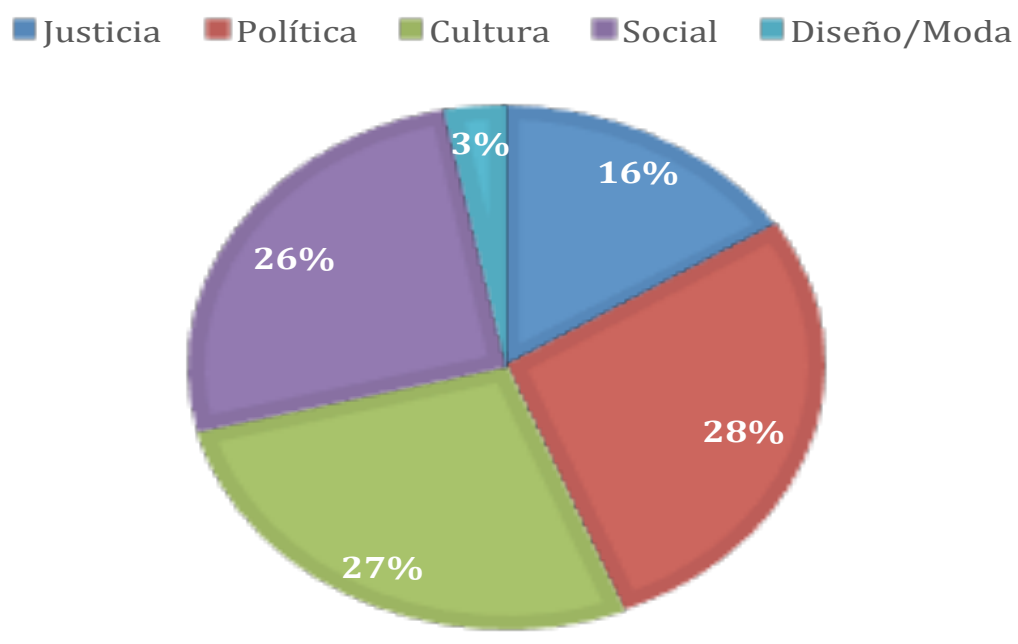

Fuente: Elaboración propia, 2013.

En el proceso de observación de participación de los usuarios activos visionado series de ficción en la televisión e interacción redes sociales, el discurso político, como subcategoría, muestra un alto porcentaje de concentración de memoria histórica en las dos producciones audiovisuales contempladas en el estudio.

\section{Conclusiones}

Estamos frente a un panorama donde todos los usuarios, a través de un yo, se convierten en un autor o narrador popularizando los comentarios en las tecnologías y medios digitales frente a las historias que se estampan en la pantalla.

La sociedad, inmersa en el uso de Internet con la hibridación de géneros y contenidos, consume no solo información y entretenimiento, sino también hechos de la realidad tratados de una manera singular por las series de ficción.

De esta forma, cuando los usuarios visualizan estos programas de televisión con temáticas históricas, responden a un deseo de hablar sobre ellas en las redes sociales donde el componente político refleja un recuerdo propio de un sistema vivido en España que queda en el olvido y conlleva, necesariamente, la construcción de opiniones en los usuarios.

Sin embargo, lo deseos de formular mensajes no se erigen sólo a contenidos políticos, sino también a tópicos sociales que se distribuyen entre modas, justicia, elementos culturales como atropellos al género femenino o componentes que se han mantenido en el tiempo como la crudeza del tratamiento policial, resoluciones judiciales o las corrupciones políticas.

La novedad de la exploración que se desprende es que los usuarios conservan un bagaje cultural de conocimientos asociativos entre pasado y presente, es decir, en la medida que las series que siguen abordan aspectos o argumentos donde la justicia no parece la correcta en el sistema, los fans no descartan en emitir mensajes que dejan claro que la situación no cambia entre una época y otra.

Mensajes relacionados con el pasado de España y su presente, aciertan, de manera irónica, que las cosas se mantienen de igual forma en el sistema social. 
En la serie Amar es Para Siempre, una muestra de 1.189 mensajes, se escogieron los usuarios que participaron en diversos comentarios, pero privilegiando quienes emitieron discursos en materia de historia.

En esta última categoría, 51 fans participaron con discursos vinculados a temáticas históricas que para el presente estudio, se seleccionaron todas aquellas apreciaciones que se relacionaban con asuntos del pasado, como así también hechos de la historia reciente donde los usuarios experimentaron acciones colectivas de la vida cotidiana.

Desde el punto de vista del uso de las plataformas de redes sociales, Facebook y Foro Formula TV genera una mayor cantidad de reflexión y opinión de los usuarios, abriendo debates que responden a conversaciones de forma positiva que beneficia la cadena de fans propia de la comunidad de seguidores de la serie Amar es Para Siempre.

No obstante, Twitter también aglutina buena cantidad de mensajes de socialización de carácter sucinto, pero con interpretaciones críticas en aspectos propios de la vida real de los 60, como así también temáticas no verosímiles para la calidad de producción de la serie.

En relación a ambas series, la red de Twitter (30\% para Amar es Para Siempre y $86 \%$ para Cuéntame Cómo Pasó) contiene la mayor cantidad de discursos asociados a la memoria de temáticas históricas, divididos en subtemas que engloban el pasado, siendo el ítem de la política lo que concita mayor discurso para evocar la memoria histórica.

En relación a la serie Cuéntame Cómo Pasó, de un total de 2.043 mensajes en las redes sociales analizadas, 57 discursos corresponden a temáticas de la historia y recuerdo del pasado, siendo Twitter y Foro los más utilizados.

Las expresiones de los usuarios logran conformar discursos que toman como referente el contexto de la historia para apelar a recuerdos de la vida cotidiana, como así también reflexionar sobre aquellos aspectos del periodo de Franco.

Para la red Twitter, los discursos son sucintos, pero con interpretaciones críticas en aspectos propios de la vida real de los 60, como así también temáticas no verosímiles para la calidad de producción de la serie.

El aspecto político, social y cultural es lo que concita mayor atención a nivel global, no sólo desde el punto de vista de visión histórica y de memoria tratada en las redes, sino también por una progresión en reiteraciones críticas del sistema donde los usuarios proyectan una continuidad en el tiempo, pese a las diferencias de época.

Para el caso de la justicia, destacan sus reflexiones, ya que para los fans que siguen ambas series, los atropellos o ineficacia del sistema son una constante continuidad en el tiempo que mantiene las mismas debilidades del pasado.

La recuperación de la memoria como contenido en la redes sociales implica la necesidad social que tienen los usuarios de hablar, analizar y discutir sobre el tema, pero que su impulso gravita en la medida en que los medios promuevan los contenidos con la formación de un guion por excelencia que despierte las sensibilidades históricas, abriendo así espacios de representación social no sólo como sistema, sino además desde lo más cotidiano que pueda generar el contenido de la realización. Los fragmentos de la historia en las redes sociales, sea institucional o individual, abre la posibilidad de una participación social que se viene generando en distintos programas mediáticos, pero en materia de recuperación histórica permite abrir interesantes reflexiones sobre la mantención de archivos históricos que pululan por las redes tecnológicas.

Estamos en presencia de una transformación social vertiginosa provocada por la tecnología donde el vínculo entre los sujetos y su correspondiente entorno, se traduce en la participación provocada por las sensaciones de las imágenes junto a la emoción, donde la televisión, el ordenador y los mensajes de manera instantánea cobran importancia en la interacción. Esta interacción donde la recuperación histórica impulsada por las series de ficción que tratan dicho género, comienza a navegar por las redes sociales y sitúa una constelación de alfabetización cuya memoria se convierte en una matriz de datos que se ubican en el espacio de la globalización.

Las series de ficción de carácter histórico, no sólo incumbe relatos de procesos, sino narraciones que están dotadas de nuevas temporalidades que investiga la realidad cotidiana de ahora o del pasado, como estructura que permite entender la experiencia humana en el marco de una realidad que devine de un pasado monumental cuyos textos discursivos persiguen no la verosimilitud de lo real, sino más bien lo esencialmente ideal sobre el corpus del texto que se manifiesta en la conducta de la sociedad en general. 


\section{REFERENCIAS}

Alonso, S. y Peyrí, T. (2013). Cuéntame. Ficción y Realidad. Barcelona, España: RBA Libros S.A.

Anania, F. (2010). La metodología de la investigación histórica y los medios de comunicación. En J.

C. Ibáñez y F. Anania (coord.), Memoria Histórica e identidad en cine y televisión. (pp.

17-37). España: Comunicación Social.

Bardin, L. (2002). Análisis de Contenido. Madrid, España: Ediciones Akal.

Bereguer, G. (2011). Factores Internos. Motivación, percepción, aprendizaje, memoria y actitudes. En A. Mollá Descals, G. Bereguer Contrí, M. Á. Gómez Borja e I. Quintallina Pardo (coord.), Comportamiento del Consumidor. Barcelona, España: Editorial UOC.

Bourdieu, M. V. (2012). Memoria social y ficción televisiva. Contexto político de la mirada de pasado. Ponencia presentada en AsAECA III Congreso Internacional de la Asociación Argentina de Estudios de Cine y Audiovisual. Universidad Nacional de Córdoba. Disponible en: http://www.asaeca.org/actas.php?pg=8\&anio=2012 (consultado el 31 mayo 2013).

Castells, M. (2009). Comunicación y Poder. Madrid, España: Alianza Editorial.

Chicharro, M. del M. y Rueda, J. C. (2008). Televisión y ficción histórica. Amar en Tiempos Revueltos. Revista Comunicación y Sociedad, 21(2), pp. 57-84.

Cuesta, U. (2006). Psicología Social de las Comunicaciones. Madrid, España: Ediciones Cátedra.

Duch, L. y Chillón, A. (2012). Un ser de mediaciones. Antropología de la Comunicación. Barcelona, España: Editorial Herder.

Erice, S. F. (2008). Memoria histórica y deber de memoria: las dimensiones mundanas de un debate académico. Revista Interdisciplinar: Monográfico, 7, pp. 77-86.

Ferro, M. (1980). Cine e Historia. Barcelona: Editorial Gustavo Gili.

Ganga, R. M. (2008). Memoria quebrada y consenso mediático de la transición. Quaderns de Cine, 3, pp. 63-77.

Garretón, M. A. (2003). Memoria y Proyecto país. Revista de Ciencia Politica, 23(2), pp. 215-230.

González Callejas, E. (2013). Memoria e Historia. Vandemécum de conceptos y debates fundamentales. Madrid, España: Ediciones Cátedra.

González Sánchez, J. (2004). Sobre la memoria. El pasado presente en los medios de comunicación. Revista HAOL, 4, pp. 153-164.

Halbwachs, M. (1968). La memoria colectiva. Zaragoza: Edición Española Prensa Universitaria de Zaragoza.

Lipovetsky, G. y Serroy, G. (2009). La pantalla global. Cultura mediática y cine en la era hipermoderna. Barcelona, España: Anagrama.

Maldonado, T. (2007). Memoria y Conocimiento. Sobre los destinos del saber en la perspectiva digital. Barcelona, España: Gedisa.

Miranda, C. (2010). Las transformaciones del relato cinematográfico y televisivo en la representación del pasado. Analecta Revista de Humanidades, 4, pp. 1-22.

Nerore, J. (1989). Professional History and Social Memory. Communication, 11, pp. 89-104.

Potter, J. (1998). La representación de la realidad. Discurso, retórica y construcción social. Barcelona, España: Paidós.

Ricoeur, P. (1999). La lectura del tiempo pasado: memoria y olvido. Universidad Autónoma de Madrid. Disponible en: http://200.95.144.138.static.cableonline.com.mx/famtz/smr/index_ archivos/cursos/Paul_Ricoeur_La_Lectura_del_Tiempo_Pasado_Memoria_y_Olvido.pdf. (Consultado 26 junio 2013).

- (1999). Historia y Narratividad. Barcelona, España: Paidós.

Sánchez Bisoca, V. (2006). Cine de Historia, cine de memoria. La representación de la realidad. Barcelona, España: Ediciones Cátedra.

Sánchez Zapatero, J. (2010). La cultura de la memoria. Revista Pliegos de Yuste, 11-12, 26-30. 
Yestes, E. (2009). El discurso de la memoria histórica en los Medios de Comunicación. Disponible en http://www.ae-ic.org/santiago2008/contents/pdf/comunicaciones/390.pdf. (Consultado 15 julio 2013).

- (2009). Los medios revisitando el pasado: los límites de la memoria. Revista Anàlisi, 38, pp. 71-80. Wodak, R. y Meyer, M. (2003). Métodos de Análisis Crítico del Discurso. Barcelona, España: Gedisa.

\section{SOBRE EL AUTOR}

Miguel Chamorro Maldonado: Licenciado en Comunicación Social y Periodista de la Universidad de Playa Ancha. Ha obtenido una Diplomatura en Estudios de Cine en la Universidad de Valparaíso y un Magíster en Gestión Cultural en la Universidad de Playa Ancha. Fue director de la revista de cine "Racontto, la mirada audiovisual impresa", ganadora de proyectos FONDART y Fondo Nacional del Libro del Gobierno de Chile. En la actualidad es Periodista de la Dirección de Extensión y Comunicaciones de la Universidad de Valparaíso y cursa el programa de Doctorado en Comunicación y Periodismo en la Universidad Autónoma de Barcelona. 